\title{
Systematic Literature Review (SLR)
}

Irawan Nurhas

Hochschule Ruhr West University of Applied Sciences

2021 


\section{Why SLR}

- (W1) Synopsis of existing research on a interventions or technologyuse.

- (W2) Identify research gaps and recommend areas for further research.

- (W3) To give a framework/background for new research efforts. 


\section{Main process of SLR}

- Planning

- Systematic screening of the literature

- Analysis

(main references: Webster $\&$ Watson, 2002; Kitchenham et al., 2009) 


\section{Planning}

- Defining the term \& context
- Narrowing down the area of investigation
- Identification of a preliminary starting point for the thematic classification
Questions




\section{Screening}

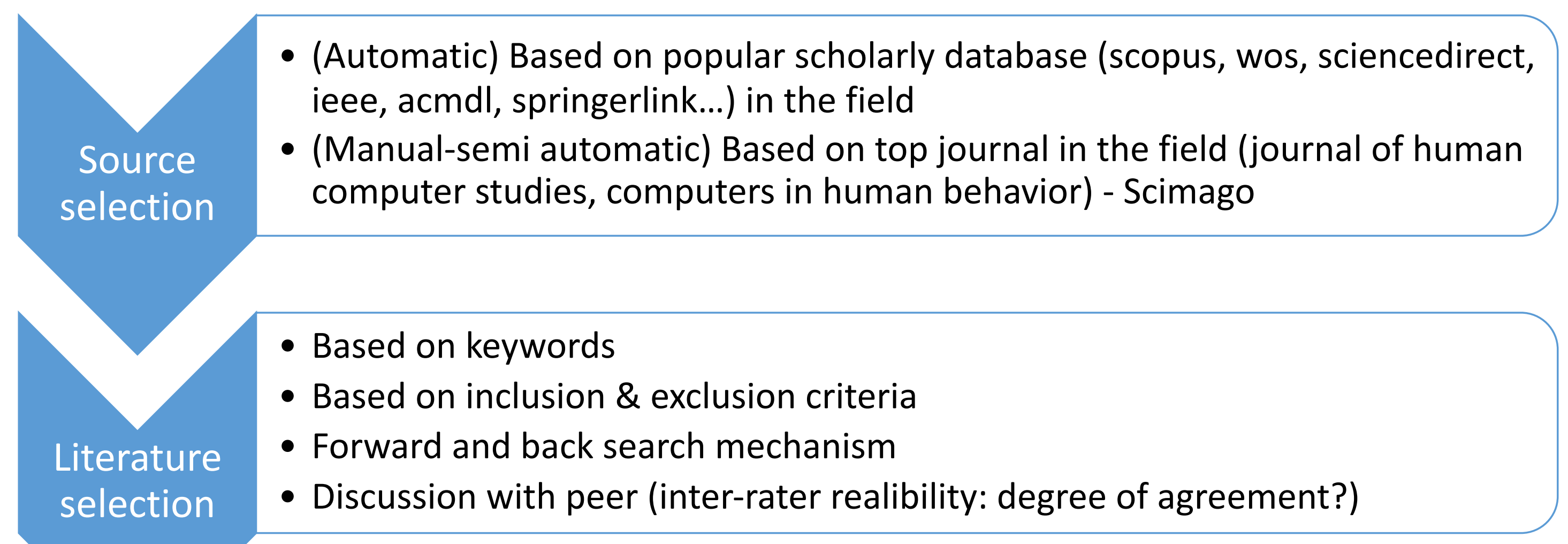




\section{Analyzing}

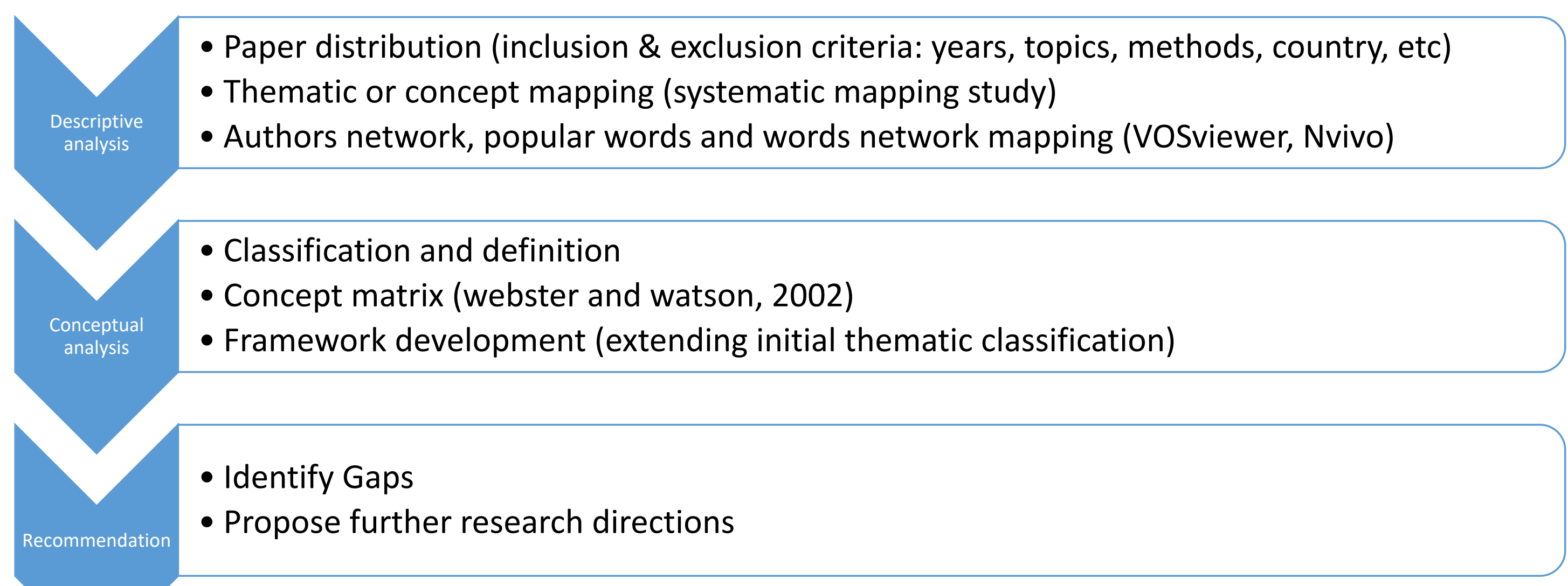




\section{References}

- Kitchenham, B., Brereton, O. P., Budgen, D., Turner, M., Bailey, J., \& Linkman, S. (2009). Systematic literature reviews in software engineering-a systematic literature review. Information and software technology, 51(1), 7-15.

- Webster, J., \& Watson, R. T. (2002). Analyzing the past to prepare for the future: Writing a literature review. MIS quarterly, xiii-xxiii. 